pag

Business School

WORKING PAPER SERIES

\section{Working \\ Paper}

2013-005

http://www.ipag.fr/fr/accueil/la-recherche/publications-WP.html

IPAG Business School

184, Boulevard Saint-Germain

75006 Paris

France

IPAG working papers are circulated for discussion and comments only. They have not been peer-reviewed and may not be reproduced without permission of the authors. 


\title{
An Empirical Study of the Determinants of Green Party Voting
}

\author{
May 17, 2013
}

\begin{abstract}
I empirically study the determinants of individuals' green voting behavior. I suggest that voting behavior is a less biased variable than commonly-used measures like willingness-to-pay and may be a better proxy for characterizing environmental attitudes. I make use of three datasets from Germany, a panel dataset and two crosssectional datasets. The empirically strongest determinants are the voters' attitude or distance to nuclear sites, the level of schooling and the net income. I show that those voters with deviant attitudes or alternative world views are more likely to vote green, a result of the fact that the green party has always had the position of a protest party. I find little role for demographic variables like sex, marital status or the number of children. This is in contrast to the stated preference literature. Age plays a role for explaining voting behavior only insofar as it proxies for health.
\end{abstract}

Word count article: 8,471 .

JEL classification: D72, Q50.

Keywords: green voting, environmental attitude, nuclear power, econometric study.

\footnotetext{
${ }^{1}$ I am grateful for comments by Luisito Bertinelli, Marc Joets, Agustin Perez-Barahona, Eric Strobl, Benteng Zou as well as the participants at the Sustainable Development Seminar of Ecole Polytechnique Paris and those at the economics seminar of the University of Luxembourg.

IPAG Business School, 184 bd Saint-Germain, 75006 Paris, Tel: +352 621264575, email: ingmar.schumacher@ipag.fr.
} 


\section{Introduction}

It is being more and more recognized that by not integrating both environmental constraints and concerns into our every-day decisions we essentially miss important feedbacks that may bear strong adverse impacts upon others or even ourselves (Stern, 2007). ${ }^{1}$ Apart from starting to accept the physical constraints where a finite planet can hardly accommodate infinite economic growth, we also understood that preferences affect how we want to shape the future that we and our children are going to live in. Decisions reflecting those preferences are then taken at two levels, the private one and the public one. While there have been many studies that try to elicit the willingness-to-pay at the private level (Torgler and Garcia-Valiñas, 2007), there have been few to none trying to understand how environmental attitudes and beliefs shape decisions at the public level. Importantly, the private preferences and actions may - for a variety of reasons - substantially differ from public preferences and actions, and consequently the way preferences transcendent into voting behavior is not always clear and cannot necessarily be extrapolated from results based on e.g. the willingness-to-pay studies. Since all environmental laws, regulations and local or nation-wide policies first have to pass through the political decision process, it is useful to know what exactly determines how this process is influenced by the voters' preferences. Thus, the objective of this article is to study the determinants of green voting.

One obvious problem lies in identifying what exactly constitutes green voting. The difficulty here is that, in general, political parties present themselves as having a multitude of objectives, and voters eventually choose parties based on bundles of promises. It is, however, also well-known that this bundling of objectives intends to attract as many voters from as diverse backgrounds as possible, while the actual decisions of the political party that comes into power mainly reflect its narrow, main party orientation. In this respect, one

\footnotetext{
${ }^{1}$ For example, a study by the US Environmental Protection Agency (2011) estimates the direct costs from the 1990 Clean Air Act Amendments and its associated programs to be roughly 65 billion USD in 2020, whereas the direct benefits are expected to be 20 trillion USD.
} 
can say the socialists tend to take more decisions with the lower and middle class in mind, the conservatives are more oriented towards the demands of the industry and the liberals towards a reduction of the welfare state. The only party that has a clear environmental focus as its top priority is the green party. The assumption here is, then, that voting for the green party in one's country reveals one's green preferences.

My hypothesis is that environmental concerns are able to predict the share of votes going to the green party. The obvious policy implication from this is that the larger the concern for the environment the larger the share of votes going to the green party and consequently the more policies will be directed towards green goals. For this study I rely on three datasets. The first dataset uses geographical data from Germany on the voting outcome from the parliamentary elections at the county level for the period 1998 to 2009 . This balanced panel dataset consists of four elections and 402 counties. I use two proxies for environmental quality, one being the share of a county's untilled area, the other being a hazard index based on the proximity to atomic power pants. The second dataset is a crosssectional dataset from the Eurobarometer study ZA3861 covering 2,835 respondents that was obtained around the 2002 election. This dataset includes a question on the attitude towards nuclear energy, which allows to compare results to those from the panel dataset. Furthermore, it has information on the respondents' place of living and additional controls which also allow to deal with some fixed effects. The third dataset utilizes the 20052008 wave of the World Value Survey, with responses from 1,343 individuals in Germany. The proxy for environmental quality is the subjective environmental belief of respondents. With this third dataset I can control further for individual-specific effects, but do not have the advantages of a panel structure. Thus, while I cannot take into account potential endogeneities or control for fixed effects, I have more detailed information on individualspecific drivers of decisions. For example, I can also study the claim that the Green party is mainly used as a protest voting parting, or whether religious denomination or the number 
of children play important roles.

The contribution to the literature is the focus on how preferences transcendent into green voting. There are few articles that have addressed a similar or related question. One article is by Crosby et al. (1981), who study the voting behavior on the 1971 Michigan Container Law. They conclude that green voting is linked to ecological concern only indirectly via behavioral intention. Based on the more detailed data I can show that ecological concern has a direct impact on green voting, where the econometric models of the panel dataset can explain up to $70 \%$ of the variance in green voting, while the models of the cross-sectional datasets can explain up to $20 \%$ of the variance.

The article also belongs to the larger literature of how preferences affect the willingness to undertake prevention expenditure or environmental behavior. A large overview of the literature is given in Turaga et al. (2010), as well as Torgler and Garcia-Valiñas (2007). While most of the studies cited in these overviews only rely on cross-sectional data, I can control further for fixed effects in the panel dataset and one of the cross-sectional datasets. Furthermore, due to the panel dataset, I can control for endogeneities, which have up to now seen little emphasis in the literature. In addition, while these studies tend to look at the willingness to undertake prevention expenditure or environmental behavior based on stated preference approaches, I look at the actual voting behavior. This has the advantage of being a more neutral measure, in the sense that it is not subject to overstatement or potential planned behavior that may never realize. For example, the gap between the willingness-to-pay, i.e. the stated preferences, and the actual behavior, is generally found to be large. This could be due to an overstatement of the willingnessto-pay due to social norms or pressures, but it could also simply be due to the fact that individuals believe that they have little effect by themselves. Consequently, while they state to have a high willingness to act green, this willingness seldomly transcendents into actual behavior. Hence, voting might be a better indicator of the willingness to act green 
since by voting green one hopes to influence governmental regulation and policies that then force everyone to act green. This storyline is linked to what Crosby et al. (Crosby, Gill and Taylor, 1981) observe in their study on the voting behavior on the 1971 Michigan Container Law. They write that "[a]t the time of the election, returnable containers accounted for less than 15 percent of consumer purchases of beer in Michigan and less than 25 percent of purchases of soft drinks (Rideout and Reyes 1976)." "In the 1976 general election the voters of that state approved by a substantial margin (64 percent to 36 percent) a proposal to require refundable cash deposits for soft drink and beer containers." Thus, voting behavior may be more tightly linked to environmental concern than measures of environmental attitudes elicited through the stated preference approach. Or, put differently, by voting green, individuals believe that the free-rider problem may be circumvented and thus their atomistic feeling will not prevent ecological concern to transcendent into actual behavior. In a previous study (Schumacher (Schumacher, 2013)) I have already shown that feelings of atomism have a negative impact on the willingness to undertake prevention expenditure.

Additionally, there has recently been some work analyzing the effects of extreme events on prevention expenditure (Schumacher and Strobl, 2011) or welfare (Barro, 2009). Here I use the hazard index that I construct in order to study whether anticipated extreme events influence green voting through beliefs or ecological preferences and thereby whether these anticipations have an effect on the political agenda.

This work is also related to that by Kahn (2007). He shows, based on census-track data for California, that the share of Green Party registered voters can explain the voting outcome on three green propositions. Thus, the more green voters the larger the share of votes going towards the preservation of green public goods. In addition, he finds that representatives from greener constituents are more likely to support environmental legislation than representatives from other constituents. What his work is missing though is a clear identification of what are the determinants of green voting. Another point relates to 
the question of local versus global environmental problems. Those voters who believe that global environmental problems are important should vote for greens because they would feel that there is a larger need for a political agenda that transcendents the local region. If that is the case, then this would show that voters believe that environmental problems also require a political platform in order to be addressed or solved. The empirical results point in precisely this direction. Thus, voters believe that national or international environmental problems require governmental regulation which will only be put in place if there are sufficiently many politicians in power that actually favor environmental regulation. Consequently, green preferences induce green voting in order to address international environmental problems.

The article is structured as follows. In section 2.1 I study the panel dataset, while in section 2.2 I focus on the more detailed cross-sectional datasets. I discuss the difference between the two datasets, the advantages and disadvantages of both, as well as the different questions that I can address. Finally, section 3 concludes with some general lessons and further questions. Readers that require a further background on green parties and the voting process in Germany are referred to the Supplementary Information material.

\section{The empirical analysis}

In this section I present the empirical analysis that underlies the results in this article. I make use of three datasets, which have some advantages and disadvantages compared to the others. One dataset is a panel dataset of geographical data from Germany at the county level, the second datasat is a cross-sectional one from the 2002 election and has responses from 2,835 individuals, while the third dataset is also cross-sectional, comes from the World Value Survey and consists of 1,343 respondants from Germany. As explained in the introduction, I place the emphasis of the empirical analysis on understanding the 
determinants of green voting.

\subsection{The panel dataset}

The panel dataset consists of the voting outcomes from the parliamentary elections at the county level for the election cycles between 1998 and 2009. This gives a balanced panel dataset consisting of four elections and 402 counties, totaling 1,617 available observations for our estimations. The elections were held 1998, 2002, 2005 and 2009. We obtained the share of the voters' second votes for the Lower House. With the second vote a voter chooses the party that he or she wishes to enter into the Lower House, and thus potentially into government. $^{2}$

We use two proxies for environmental quality, one being the share of a county's untilled area, the other being a hazard index based on proximity to atomic power pants. Furthermore, we use two controls, namely the share of those without a lower secondary education to the number of potential voters, ${ }^{3}$ as well as the per capita after-tax income (available income), both at the county level.

The hazard index is constructed as follows. I obtained the GPS coordinates of each atomic power plant and final atomic disposal site in Germany and in close proximity to Germany. ${ }^{4}$ I then constructed a hazard index based on the Haversine distance ${ }^{5}$ according to the formula

$$
\operatorname{Hazard}_{i t}=\sum_{j} \frac{1}{d_{i j_{t}}}
$$

\footnotetext{
${ }^{2}$ In contrast, a voter's first votes are more personal and may be less based on party orientation. With the first vote, a voter chooses his favorite candidate that may directly enter the Lower House.

${ }^{3}$ The age structure should be very similar across counties, so per capita or per voter should give equivalent results.

${ }^{4}$ The empirical results had only marginal quantitative changes when I calculated the hazard index based on German atomic power plants only.

${ }^{5}$ The Haversine distance is calculated as $d=2 r \arcsin \left(\sqrt{\sin ^{2}\left(\frac{\theta_{2}-\theta_{1}}{2}\right)+\cos \left(\theta_{1}\right) \cos \left(\theta_{2}\right) \sin ^{2}\left(\frac{\lambda_{2}-\lambda_{1}}{2}\right)}\right)$, where $d$ is the distance, $r$ is the radius of the earth, $\theta_{1}$ and $\theta_{2}$ the latitudes of point 1 and $2, \lambda_{1}$ and $\lambda_{2}$ the longitude of point 1 and 2 .
} 
where the hazard index $H_{i t}$ of each county $i$ at time $t$ is an aggregate of the inverse functions of the distance $d_{i j_{t}}$ of county $i$ 's center to each nuclear site $j_{t}$. It is time varying because of the changing number of nuclear power sites. ${ }^{6}$ Thus, the closer a county is to a nuclear power site the higher will be its hazard index. Individual hazards are calculated as an inverse function of the distance in order to emphasize that someone living very close to a nuclear power plant will view it as a large hazard, with no potential to react in case of a large-scale accident, while someone further away will be much less or little concerned by it. Another concern captured by the hazard index is that of potentially continuous exposure to increased radiation. ${ }^{7}$ An example for the hazard index in 2009 is given in Figure $1 .{ }^{8}$ We see that most nuclear power plants or hazardous waste sites are in western Germany. As a result, the hazard index in these counties takes on higher values, indicated by the darker red surfaces. We forward the following hypothesis.

\section{Hypothesis 1 A higher hazard index induces more green voting.}

The basic hypothesis is that voters face a continuous fear of large-scale accidents at nuclear sites. Hence, voters that are living closer to nuclear sites have a stronger overall fear of nuclear accidents and the hypothesis is that they are consequently more likely to vote for the green party.

\section{Hypothesis 2 Less natural area induces more green voting.}

With respect to the other environmental variable, namely the share of untilled area within a voter's county, the hypothesis is that the larger this share the less likely are voters going to

\footnotetext{
${ }^{6}$ Two power plants were closed during that period, one in 2003 and one in 2005 . The variability in the fixed effects estimations for the hazard index comes from those two closures.

${ }^{7}$ There has been a long-standing debate on whether an increased number of leukemia cases occurs in closer proximity to nuclear sites or not. While scientific proof of this is still not final, there is still the fear of a potential positive relationship.

${ }^{8} \mathrm{~A}$ suggestion for another hazard index would be to use the accidents reports accumulated during a period of time for each nuclear power plant. Those plants with more accidents would be viewed as having a higher hazard. Though this may be possible, few information on accidents at nuclear power plants get leaked to the public, and it does not seem to be common practice to obtain the individual accident reports. Furthermore, a weighting according to the distance would still be necessary.
} 
vote for the green party. This comes from any economic model where a lower environmental quality induces a higher willingness-to-pay for the environment. Consequently, one would also expect more votes going to the party that is most likely to increase environmental quality in that county. We discuss and treat potential endogeneities in the next section.

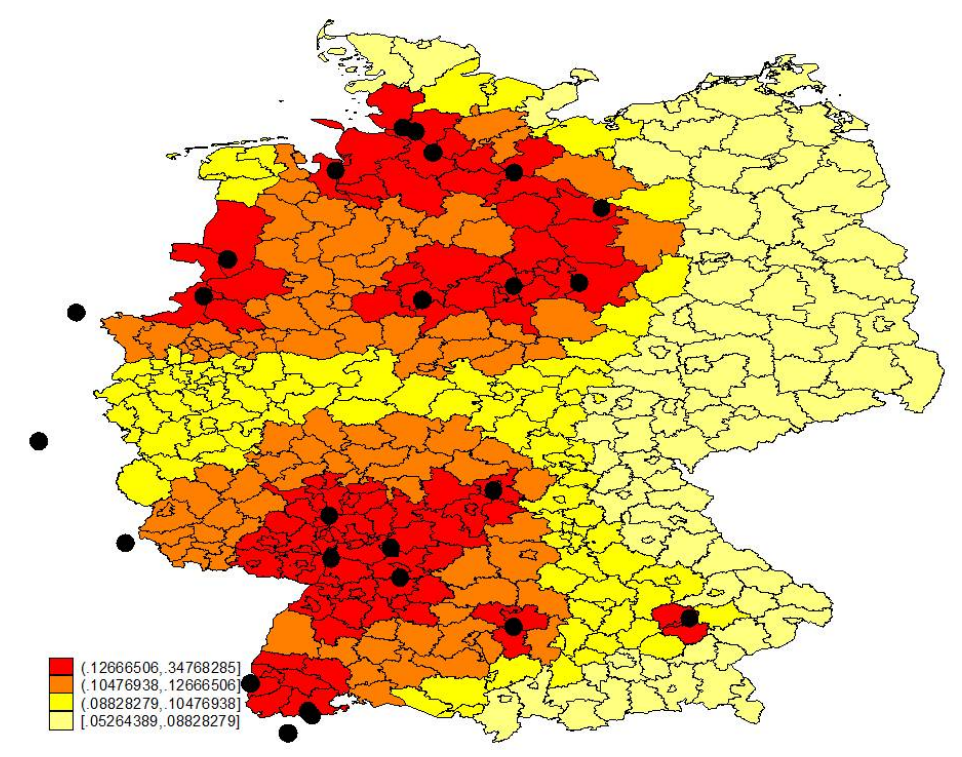

Figure 1: Hazard index 2009

The other variables are the share of those without a lower secondary education to the number of potential voters, as well as the per capita after-tax income (available income) of the households.

Hypothesis 3 A higher income leads to more green voting.

This hypothesis is related to the ability to undertake prevention expenditure, or the ability to free resources for environmental taxes. Obviously, the higher the net income of voters the more money they are likely to have that they may be willing to spend on the environment. This channel has already been shown to hold in cross-sectional willigness-to-pay studies by e.g. Stevens et al. (1994), Popp (2001), or Isael and Levinson (2004).

Hypothesis 4 A better educational level induces more green voting. 
The higher educational level should be associated with a better knowledge of the linkages between the economic world and the environment, or a better understanding of one's own impact on nature. Previous cross-sectional studies based on stated preferences that found linkages between the educational level and the willingness-to-pay for the environment are e.g. Blomquist and Whitehead (1998), Danielson et al. (1995), and Engel and Pötschke (1998). 


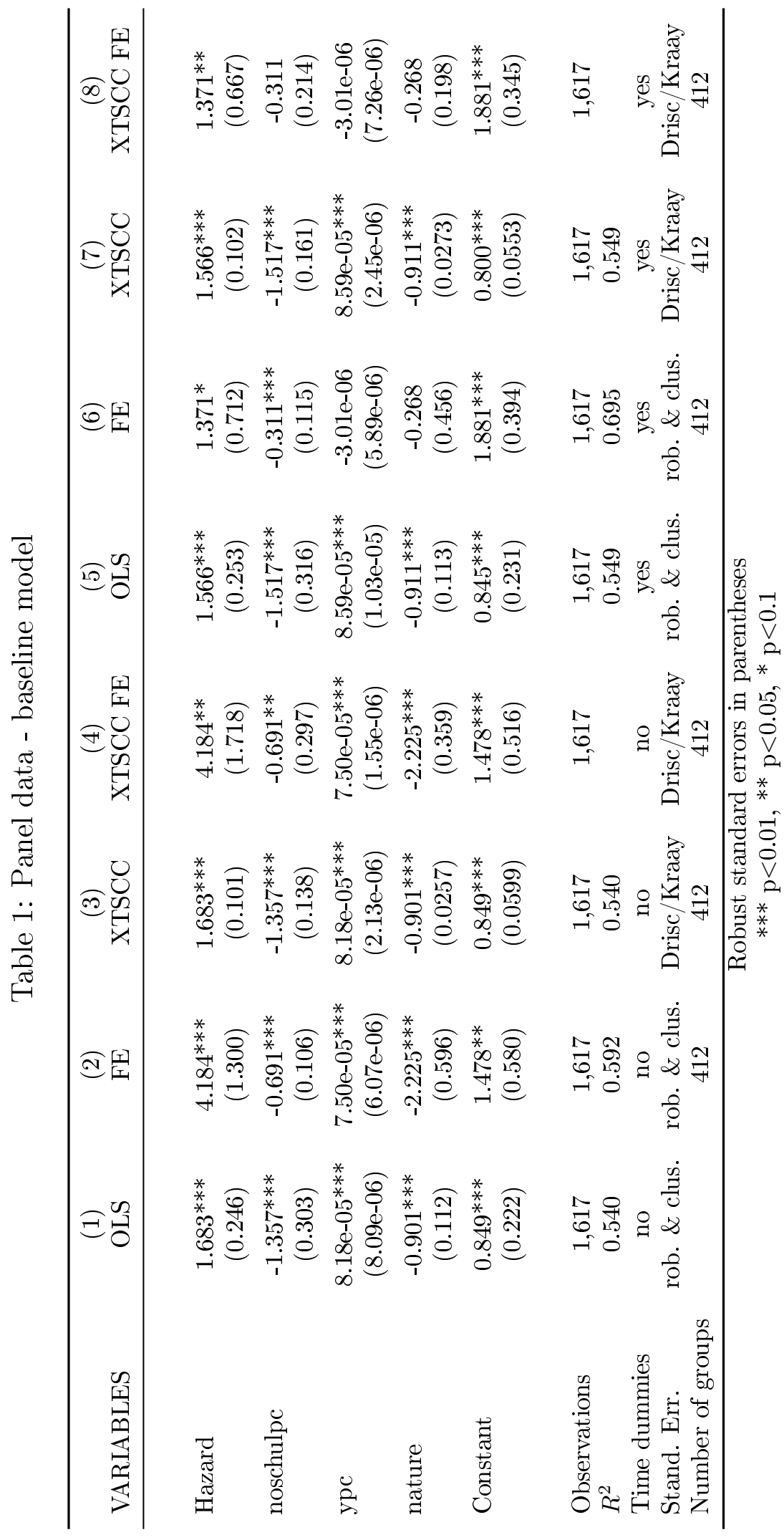


Summary statistics are available in Table 2 for the full dataset used in the models of Tables 1 . We begin by a straight-forward estimation of the basic model via ordinaryleast squares (OLS), model (1), and a fixed effects estimator, model (2). Both models use the Huber-White correction for the standard errors in order to correct for possible heteroscedasticity, and furthermore standard errors are clustered at the county level. Thus, the results should be heteroscedasticity-robust and cluster-robust. The baseline OLS model (1) explains $54 \%$ of the variance in the green voting outcome across counties. Allowing for fixed effects in model (2) increases the R-squared only little, to $59.2 \% .^{9}$ Thus, the Hazard index, the schooling level, income per capita and the share of untilled area are able to explain somewhat more than half the variance in green voting and are all highly statistically significantly different from zero. A unit increase in the Hazard index increases the percent of green votes by 1.68 in the OLS estimator and by 4.184 in the fixed effects estimator. This is the result that was to be anticipated: the closer voters live to nuclear sites the more likely are they going to vote for the green party. The larger the share of voters with lower educational levels the fewer votes go to the green party (OLS coeff -1.356 ; FE coeff -0.691). Consequently, higher levels of schooling improve the attitude towards green values. The fixed effect estimator is the preferred model, since the results indicate that the correlation between the fixed effects and the explanatory variables is quite high $\left(\operatorname{corr}\left(\mathrm{u}_{i}\right.\right.$, $\mathrm{Xb})=-0.58$ ), which would render the OLS estimator inconsistent.

The models (5) and (6) include time dummies, which have little impact on the OLS estimator but render income per capita and the share of untilled area statistically insignificant in the fixed effect estimator. Nation-wide annual shocks thus seem to play a significant role only for the fixed effects estimator, which is now able to explain $69.5 \%$ of the overall variance of green voting. One likely reason for the difference in the OLS and the FE estimator in the case of time dummies is that the FE estimator only uses within data. It

\footnotetext{
${ }^{9}$ However, the fixed effects are statistically highly significant.
} 
is, for example, well-known that income per capita or schooling levels improved steadily during the past years, and these trends could have been captured by the time dummies. As a consequence, it could be worthwhile to investigate whether autoregressive processes (for example in ypc or noschulpc) played a role for our results. For this we rely on the estimator by Hoechle (2007) that uses the Driscoll and Kraay standard errors (Driscoll and Kraay, 1998). They are able to correct for arbitrary kinds of autocorrelation and heteroscedasticity. Results without time dummies are shown in model (3) and (4), with time dummies in models (7) and (8). While models (3) and (4) have no significant differences to their OLS and FE counterparts, and neither has model (7), the fixed effects estimator with Driscoll and Kraay standard errors in model (8) also loses significance for the schooling variable. Thus, the only variable that can consistently explain green voting behavior is the Hazard index.

Table 2: Summary statistics: Panel data

\begin{tabular}{lccc}
\hline \multicolumn{1}{c}{ Variable } & Mean & Std. Dev. & N \\
\hline $\log \left(\operatorname{greenpc}_{i t}\right)$ & 1.642 & 0.462 & 1,617 \\
Hazard $_{i t}$ & 0.181 & 0.061 & 1,617 \\
noschulpc $_{i t}$ & 0.129 & 0.051 & 1,617 \\
ypc $_{i t}$ & 16879.568 & 2639.97 & 1,617 \\
nature $_{i t}$ & 0.796 & 0.152 & 1,617 \\
\hline
\end{tabular}

\subsubsection{Dealing with endogeneity}

The estimators that we used in the previous section are standard estimators that are able to correct for some problems like heteroscedasticity, clustering or autocorrelation. However, problems of endogeneity are possible and should not be neglected. For example, as an environmentalist I might have an aversion to nuclear power plants and thus not move close to one. Consequently, there should be another variable, like the endogenous choice where 
to live, that affects both the explanatory variables and my choice of voting green. Or, in the words of Tiebout, "[t]he consumer-voter may be viewed as picking that community which best satisfies his preference pattern for public goods." (Tiebout, 1956, p. 418) The previous estimators did not take this kind of endogeneity into account. Therefore, under Tiebout sorting of individuals or households, we expect our variables to be pre-determined. This implies that, among the possibility that e.g. the coefficient on the Hazard index in the OLS or FE estimators actually understates the impact from hazard to green voting, and thus the true aversion to nuclear sites, that our estimations are not consistent. In this case a first-difference estimator would help in resolving this kind of endogeneity, since the first-difference estimator allows for weak exogeneity (Engle et al. (1983)).

Another source of endogeneity is that, for those counties in which the green party is governing, it is likely that there is an impact on the Hazard index via nuclear sites that the green party prevents from being built. This kind of endogeneity would also violate the strict exogeneity assumption of the FE estimator, since the error at time, $\epsilon_{i t}$, would impact the explanatory variable $H_{i t+1}$.

Finally, recent research on endogenous preferences has been able to show that there are dynamic interactions between green preferences and the environment. Articles that study this aspect are, for example, Nyborg et al. (2006), Buenstorf and Cordes (2008), Schumacher (2009). The main idea that these articles have in common is that social norms or other incentives lead to changes in the proportions of people that have green preferences and those that are less environmentally-concerned. Thus, there may be other drivers that determine both ecological concern and green voting at the same time.

Consequently, I supplement the previous results with two estimators that are specifically designed to deal with endogeneity. One is the first difference (FD) estimator, which allows the explanatory variables to be weakly exogenous. ${ }^{10}$ In contrast, if even weak exogeneity is

\footnotetext{
${ }^{10}$ This means that $E\left(\epsilon_{i t} \mid \alpha_{i}, x_{i 1}, \ldots x_{i t}\right)$, where $\epsilon_{i t}$ is the error term at time $t, \alpha_{i}$ the fixed effects, and
} 
Table 3: Panel data - accounting for endogeneity

\begin{tabular}{|c|c|c|c|c|}
\hline VARIABLES & $\begin{array}{l}(9) \\
\text { FD }\end{array}$ & $\begin{array}{l}(10) \\
\text { FD }\end{array}$ & $\begin{array}{l}(11) \\
\mathrm{AB}\end{array}$ & $\begin{array}{l}(12) \\
\mathrm{AB}\end{array}$ \\
\hline D.Hazard & $\begin{array}{c}9.064^{* * *} \\
(1.645)\end{array}$ & $\begin{array}{c}2.775^{* * *} \\
(0.926)\end{array}$ & & \\
\hline D.noschulpc & $\begin{array}{c}-0.565^{* * *} \\
(0.111)\end{array}$ & $\begin{array}{l}-0.209^{*} \\
(0.108)\end{array}$ & & \\
\hline D.ypc & $\begin{array}{c}8.93 \mathrm{e}-05^{* * *} \\
(5.36 \mathrm{e}-06)\end{array}$ & $\begin{array}{l}-7.34 \mathrm{e}-06 \\
(5.47 \mathrm{e}-06)\end{array}$ & & \\
\hline D.nature & $\begin{array}{c}-2.918^{* * *} \\
(0.668)\end{array}$ & $\begin{array}{l}-0.405 \\
(0.454)\end{array}$ & & \\
\hline Hazard & & & $\begin{array}{c}11.97^{* * *} \\
(2.629)\end{array}$ & $\begin{array}{c}13.22^{* * *} \\
(3.261)\end{array}$ \\
\hline noschulpc & & & $\begin{array}{c}-1.429^{* * *} \\
(0.431)\end{array}$ & $\begin{array}{l}-1.354^{*} \\
(0.728)\end{array}$ \\
\hline ypc & & & $\begin{array}{c}0.000357^{* * *} \\
(7.14 \mathrm{e}-05)\end{array}$ & $\begin{array}{r}0.000338^{* *} \\
(0.000164)\end{array}$ \\
\hline nature & & & $\begin{array}{c}-9.051^{* * *} \\
(2.969)\end{array}$ & $\begin{array}{l}-7.716 \\
(8.547)\end{array}$ \\
\hline $\begin{array}{l}\text { Observations } \\
R^{2}\end{array}$ & $\begin{array}{l}1,205 \\
0.503\end{array}$ & $\begin{array}{l}1,205 \\
0.641\end{array}$ & 1,205 & 1,205 \\
\hline Time dummies & no & yes & yes & yes \\
\hline Stand. Err. & robust & robust & robust & robust \\
\hline Number of groups & & & 402 & 402 \\
\hline Number of instruments & & & 12 & 8 \\
\hline Sargan p-val. & & & 0.031 & 0.854 \\
\hline Hansen p-val. & & & 0.285 & 0.881 \\
\hline $\operatorname{AR}(1)$ p-val. & & & 0.506 & 0.389 \\
\hline $\operatorname{AR}(2)$ p-val. & & & 0.121 & 0.0923 \\
\hline
\end{tabular}

Robust standard errors in parentheses

${ }^{* * *} \mathrm{p}<0.01,{ }^{* *} \mathrm{p}<0.05,{ }^{*} \mathrm{p}<0.1$ 
not satisfied, then the explanatory variables are endogenous and must be treated as such. I make use of the particular structure of this dataset, namely the short ' $\mathrm{T}$ ' but large ' $\mathrm{N}$ ' structure, which allows to take instrumental variables from inside the dataset itself, namely the lagged values of the explanatory variables. The estimator is called Arellano-Bond (AB), see Roodman (2009). ${ }^{11}$ The results for both estimators are presented in Table 3 . There are several criteria for the Arellano-Bond estimator that need to hold before the results can be trusted. The first two tests are the Arellano-Bond $\operatorname{AR}(1)$ and $\operatorname{AR}(2)$ tests, which test for autocorrelation in the errors. In order for these tests to be valid, there should not be any cross-county correlation. For this reason it is necessary to run the Arellano-Bond estimator with time dummies (Roodman, 2009). In addition, there is the Sargan and Hansen test for instrument validity. In contrast to the Sargan test the Hansen test is robust but weakened by many instruments. A rule-of-thumb is that the number of instruments should be less than the number of counties.

Qualitatively, I find no differences to the previous results. There are marginal quantitative differences, for example the coefficient on the Hazard index is larger when accounting for endogeneities. Results with the first-difference estimator and Arellano-Bond estimator are approximately the same. The differences between the models is that the first-difference estimator in model (9) does not include time dummies while model (10) does. The results of model (10) conform very closely to those of models (6) and (8). Models (11) and (12) are based on the Arellano-Bond estimator and differ only in the choice of instruments. While both pass the instrument validity tests, model (12) shows somewhat lower levels of significance for the schooling variable, for income per capita, and the share of untilled area is statistically insignificantly different from zero.

$x_{i 1}, \ldots x_{i t}$ the observations on the explanatory variables prior to date $t$. This weakened assumption, in contrast to that for the $\mathrm{FE}$ estimator, allows future values of the explanatory variables to be correlated with the error term.

${ }^{11}$ Though this estimator is generally used for dynamic panels, it is equally-well applicable to static ones, see e.g. Blundell et al. (1992). 
As an overall conclusion from the panel data, I suggest to take the following away. Proximity to nuclear sites should increase the fear of one's own inability to react on time in case of nuclear disasters. The econometric results suggest that the closer voters live to nuclear sites the more likely they are to vote for the green party. Using the results from model (11), when holding all other variables at the sample mean, we find that moving from the minimum value of the Hazard index to its average level increases green voting by two percentage points. In addition, lower levels of education are associated with lower green votes, suggesting that educational attainment plays the role of information provision or an increased critical thinking. Reducing the share of less educated in a county from the maximum to the average leads to an increase in green votes of one percentage point. Further, net income per capita tends to have a positive impact on the share of green votes in a county, implying that only wealthier households who actually have the ability to be green ${ }^{12}$ also support that their attitudes turn into government policies. Also, green parties tend to focus less strongly on economic growth and financial remunerations. Consequently, poorer individuals may prefer to vote for parties that focus more strongly on incomegenerating policies. Increasing the net income per capita from its minimum to its average level while keeping all other variables constant increases the share of green votes by 2.4 percent. The share of untilled area in a voter's county may play the role of diminishing incentives for green voting, though this result is not statistically robust across the different specifications. Relying on model (11) again, a reduction from the maximum to the average level of the untilled area increases green voting by 2.2 percent.

\footnotetext{
${ }^{12}$ For example, ecolabeled products tend to be more expensive than their conventional, brown counterparts.
} 


\section{$2.2 \quad$ The cross-sectional datasets}

I make use of two cross-sectional datasets, one utilizes the Eurobarometer study ZA3861, the other is based on the 2005-2009 wave of the World Value Survey. The econometric models are available in the Supplementary Information material.

\subsubsection{Cross-section dataset 1}

This first cross-sectional dataset is based on the Eurobarometer study ZA3861 from 2002. This dataset is specifically designed to understand voters' attitudes in Germany before and after the 2002 election. It is based on a questionnaire where interviewers tried to elicit the expected voting behavior before the election, and also the actual voting behavior after the election. Furthermore, a set of control questions is available. The summary statistics are collected in Table 4, and the complete variable description is given in Table 6.

There are three main advantages of this dataset compared to the one from the World Value Survey. The first advantage is a question on the attitude towards nuclear energy. Basically, respondents are asked to state whether they want the use of nuclear energy in Germany to be further increased, or whether they prefer an immediate stop of nuclear power plants. While the panel dataset was only able to control for the distance to a nuclear power plant, or the potential hazard of living close one (or several), it is now possible to know the general attitude of individuals and how this may affect the voting

behavior. The second advantage is that this survey gives information on which federal state respondents live in. Hence we can control for fixed effects that may be specific to a federal state. The third advantage is that, in the dataset from the World Value Survey, the only information on voting that we have is what party respondents vote for. However, we do not know whether this applies to elections for the Lower House, the Upper House, or for European voting. Thus, in terms of responses, this dataset and the panel one are, at least theoretically, more easily comparable. 
Overall there are 2,835 respondents in our sample. The percent of green voters is 6.9. This matches well the county-average percent of green votes in the panel dataset, which is 6.06. I resort to a logit estimator since the dependent variable is dichotomous. Standard errors are corrected via the Huber and White sandwich estimator, which is able to correct some misspecification as long as observations are independent. To insure independence, I cluster at the federal state level. Estimation results are depicted in Table 5, and odds ratios are presented. Half of the respondents were sampled before the election, while half were sampled afterwards. Hence, around $50 \%$ of respondents stated their expected voting behavior, while the others stated the vote they actually casted. To control for potential differences I add a dummy variable called election, which takes the value of zero for a pre-election interview, and the value of one for a post-election interview. ${ }^{13}$

In order to test for model misspecification, I make use of the Hosmer-Lemeshow test (HL test) with 10 groups, as well as the Langrange Multiplier test (LM test), also known as Stukel score. The HL test has the null hypothesis that the sample frequency of the dependent variable is the same as the one of the fitted probabilities of observation subgroups. The ML test analyses whether a generalized h-family logit model fits the data better, with the null hypothesis being that the model is correctly specified. ${ }^{14}$ The p-value in the ML test corresponds to the p-value of the non-linear regressor. In all cases apart from model (15) it is not possible to reject the null hypothesis. In model (15) the p-value for the ML test is 0.04, which is below the critical value, and the null hypothesis of correct model specification should be rejected. However, the only difference between model (15) and model (16) is that model (16) includes federal state dummies. Both the sample and the regression results are the same, and it is not possible to reject the null hypothesis of

\footnotetext{
${ }^{13}$ I also ran separate regression, one constrained to the pre-election sample, one to the post-election sample, and compared coefficients across the regressions. There were never any significant differences. Thus, intended voting behavior is sufficiently close to actual voting behavior, such that it makes sense to combine the information in one regression.

${ }^{14}$ Both the HL test and the ML test are explained in Cameron and Triveda (2009).
} 
the ML test in model (16). Consequently, it is unlikely that model (15) is mis-specified, despite the test results.

Models (13) and (14) present the benchmark case, where the explanatory variable is the subjective attitude towards nuclear energy. The coefficient on nuclear energy is highly statistically significant (coeff $4.404^{* * *}$ ). It implies that for someone who believes nuclear energy in Germany should be stopped the odds for voting the green party are 4.4 times higher than for someone who believes nuclear energy is useful for Germany. In model (14) I add federal state dummies in order to control for fixed effects like eastern-western disparities, regional differences in traditions or natural sites that are not surveyed in the interview and may drive the results. As one can see, this has no significant impact on the estimation results.

In models (15) to (17) I add additional controls. The first set of controls in models (15) and (16) are the educational attainments, stated interest in politics, satisfaction with the previous government, and how often respondents watch news on national TV. In addition, model (16) includes the federal state dummies, which leads to no significant differences in results. The benchmark for educational attainment is having passed lower secondary education. As one would expect, there are no differences in voting behavior between those who are still in school and completed their lower secondary education. However, for increasing levels of educational attainments, the odds for voting the green party increases, with all coefficients being highly statistically significant. For example, the odds for voting for the green party are between 4.698 and 5.067 higher for someone with a university degree than for someone with a lower secondary education. This result is in line with the one from the panel dataset. Educational attainment plays a role for green voting behavior. This is most likely the case because more highly educated have a better knowledge of the environmental problems and the way mankind impacts the environment. Or they are more strongly used to critical thinking or influenced by the social norms of their educational class. 
Another possibility could be that more highly educated respondents are also likely to have a higher income and thus a higher willingness-to-pay for the environment. To see which explanation is the more likely one I added the variable social status in model (17). As it turns out, this variable is statistically insignificantly different from zero. Similarly, income classes (results available from the author) turn out to be unable to explain differences in voting behavior. ${ }^{15}$ As a consequence, this empirical analysis suggests that we should align ourselves with the explanation that is based on knowledge differences. This result is in line with those on educational attainments in e.g. Blomquist and Whitehead (1998), Engel and Pötschke (1998), Danielson et al. (1995) and Schumacher (2013), but it somewhat contradicts results on the impact of wealth or social class on the willingness to undertake prevention expenditure in other studies, e.g. Stevens et al. (1994), Popp (2001), Isael and Levinson (2004) and Schumacher (2013). Furthermore, it contradicts the findings from the panel dataset, where net income per capita turned out to be a significant driver of green voting behavior across counties. One reason for the differences in results is that the panel dataset includes final income per capita which is available for consumption or investment expenditure, while in the cross-sectional dataset the only information available is the social status or the income class (before taxes). Differences in social status may not be a good proxy for income differences since that is a subjective assessment and may not e.g. correspond fully to the ability to undertake e.g. green expenditure. Also, income classes may not be highly correlated with net income per capita if there are important regional differences between net available income and income classes.

The interest in politics is highly statistically significant, with a coefficient in the range of 1.613 to 1.697 . Thus, the odds of voting green increase by a factor of roughly 1.65 for

\footnotetext{
${ }^{15}$ One could imagine that educational classes in the cross-sectional dataset 1 are able to provide more information than in the panel dataset and this information is highly correlated to income classes or the social class. However, even without educational classes in the cross-sectional regression, neither income nor social class has a statistically significant impact. I also tried different ways of including income into the model, linear and non-linear, as individual income group dummies and as a simple dummy. None showed up statistically significantly different from zero.
} 
those interested in politics compared to those that show little interest. As for the variable government satisfaction, someone who was satisfied with the previous government, namely the coalition between SDP and the green party, would have been expected to vote for the green party also in the 2002 election. This is also what the estimation results suggest. The odds of voting green are between 5.3 to 5.6 times higher for someone who was satisfied with the green party's performance during the last governmental cycle compared to someone who was unsatisfied. This result is highly statistically significant. Finally, those voters who regularly watch national news on TV are less likely to vote for the green party. Indeed, the odds for voting green are now below one (between 0.635 and 0.642 ) for those who follow national news regularly. This highly statistically significant result is, nevertheless, not too surprising. The news program on those two TV channels has always had a rather conservative approach. For example, the style of the news program on the first and second channel has been basically the same for the past 60 years since these TV channels have been established.

Finally, model (17) includes additional standard controls, namely sex, marital status, social status, all of which turn out to be statistically insignificantly different from zero. I also include a variable asking the opinion of voters whether they view the party programs as being different from each others. This last variable also turns out to be unable to explain differences in green voting. Neither of these additional controls has an impact on the previous statistical results. ${ }^{16}$

\subsubsection{Cross-section dataset 2}

This second cross-sectional dataset utilizes the 2005-2008 wave of the World Value Survey, with responses from 1,343 individuals in Germany. With this second dataset one can control

\footnotetext{
${ }^{16}$ The sample size for model (17) is lower than for the other models due to missing observations in these controls. Re-running models (13) to (16) based on the sample of model (17) does not lead to different results.
} 
further for individual-specific effects, but does not have the advantages of a panel structure. Thus, while it is not possible to take into account potential endogeneities or control for fixed effects, this dataset includes more detailed information on individual-specific drivers of voting decisions. Also, it is possible to exploit different environmental variables that are unavailable in the other datasets. They can serve as a control for the previous results. A detailed description of the variables is given in Table 7, with their summary statistics in Table 8. Just like for the cross-sectional dataset 1, I ran tests for model misspecification. Both the HL and ML tests for models (18) to (21) do not indicate that the models in Table 9 suffer from misspecification.

While this dataset unfortunately does not include information on the respondents' attitude towards nuclear energy, there is further information on the respondents' attitude towards local and global environmental problems that is possible to be exploited. Specifically, the proxy for environmental quality is the subjective environmental belief of respondents. I construct three variables that include averages of the respondents' beliefs on local environmental problems, global environmental problems, and both combined. The variable gr_loc combines respondents' assessments of how serious they view problems of water quality, poor air quality, poor sewage and and sanitation in their community. The larger is gr_loc the less serious is the subjective view of the problems. Similarly, variable gr_glo combines views on global warming or the greenhouse effect, the loss of plant or animal species or biodiversity, and the pollution of rivers, lakes and oceans in the world. Again, the larger is gr_glo, the less serious is the subjective view. Finally, variable gr _ $\mathrm{i}$ adds the replies to both variables.

In addition to variables that are similar to those from the cross-sectional dataset 1 (sex, marital status, religious, education, conf_gov, interest), this dataset allows to control for further effects via additional variables. These additional variables include a subjective health assessment, variable health, where a respondent scoring a one assesses his health 
status as being better than someone scoring a zero. The hypothesis here is that those respondents with a worse health situation would be more likely to vote for the green party. ${ }^{17}$ In addition, I include a variable called urban, where respondents that score a one live in a city with more than 50,000 inhabitants (and thus in a more urban centre), while those living in an area with less than 50,000 inhabitants score a zero (and thus live more rural). The hypothesis is that respondents from urban centres are likely to have different views about environmental issues than those that live in more rural centres.

Furthermore, the green party in Germany has always had an approach and attitude of a group that wants to transform, wants to change traditions and wants to protest. For example, when the green party entered the Lower House in Germany for the first time, their members did not show up in suits but in every-day clothing, with long hair and beards. This was certainly unthinkable during that time. In addition to their outside appearance, their party program and their objectives were more radical, more oriented towards transforming the society than keeping up the old ways. Based on this one would believe that the green party would also be more likely to attract voters that hold these deviant or alternative views. In order to assess the importance of this potential explanation, I use two variables, just_deviant and just_altern. Variable just_deviant measures whether respondents find it justifiable to behave in a deviant way, including unrightful claiming of government benefits, avoiding a fare on public transport, cheating on taxes, or someone accepting a bribe. Variable just_altern measures whether respondents find homosexuality, prostitution, abortion, divorce or euthanasia justifiable. Thus, while variable just_deviant measures the potential for respondents to undertake deviant behavior ${ }^{18}$ and thus to overstep laws, with the variable just_altern it is possible to extract respondents' views on the importance of several social norms and thus about how they think outside of the established

\footnotetext{
${ }^{17}$ There is a growing literature on health and the environment, see e.g. Mariani et al. (2010).

${ }^{18}$ This assumes that there is a sufficiently strong correlation between someone believing that it is justifiable to undertake deviant behavior and someone actually undertaking this behavior.
} 
box.

The regression results are presented in Table 5, the coefficients being the odds ratio. Model (18) is the benchmark case and includes the overall index of the respondents' assessment of environmental problems, the subjective health assessment and the educational attainment. All variables are highly statistically significantly different from zero. The results suggest that respondents who view environmental problems as being less serious are likely to vote less for the green party than those that view the problems as more serious (coeff 0.911). As in the cross-sectional dataset 1 and in the panel dataset, the results on educational attainment show that those respondents that are more highly educated are also more likely to vote for the green party. Surprisingly, model (18) suggests that those respondents that rate themselves as having a better health are also those that vote more for the green party (coeff 2.122). While this is counter-intuitive at first sight, the solution to this puzzle is given in model (19). Here we add further controls and the only additional one that comes up as highly statistically significant is age. However, in model (19), and in contrast to model (18), the health measure is not anymore statistically significantly different from zero. The answer, thus, lies in the relationship between age and health. Within our sample, the correlation coefficient between age and health is -0.37 and it is highly statistically significant. Thus, younger respondents are, on average, blessed with a better (subjective) health status and are also more likely to vote for the green party (coeff 0.97). Consequently, health plays a role for green voting only insofar as it is affected by age, which itself is a determinant of green voting.

In model (20) I split the environmental assessment variable into its local and global counterparts. While the previous results of model (19) are unaffected by this split-up, I find that only global environmental problems help in explaining green voting behavior (coeff 0.814). The worse a respondent's assessment of global environmental problems, the more likely will the respondent vote for the green party. Based upon this one could be inclined 
to believe that green voting is only related to global environmental problems. This would stand in contrast to the panel data results and those from the first cross-sectional dataset, where the hazard index or nuclear energy had a negative impact on green voting. This gives rise to two potential explanations. One, Germans do not necessarily view the hazards from nuclear energy as only a local problem, but a disaster may be seen as having global effects. Chernobyl is an example for this. Against this explanation would speak the statistically highly significant impact of the hazard index on green voting. Though physical distance to a nuclear site may also be interpreted as a psychological distance to a potential disaster, the more likely explanation is that individuals feel safer the further they are away from a nuclear site (in terms of disaster potential and health issues). Thus, local environmental issues should matter. And this is also what the significance of the second environmental variable in the panel dataset, the share of the untilled area in a voter's county, suggests. Hence, a second explanation could then be that the local environmental problems that are being asked for in the second cross-sectional dataset, namely water quality, poor air quality and poor sewage and sanitation, are negligible in Germany. And this is precisely what is the likely explanation. While the sample mean for global problems is at 5.08, the one for the local problems is at 9.23. The minimum for gr_loc or gr_glo is 3, while the maximum is 12. Thus, most respondents view local problems as not being serious at all, while they find global environmental problems as being very serious. ${ }^{19}$

In the final model (21) the additional variables are just_deviant and just_altern. Both show up highly statistically significant and with a similar odds ratio (coeff 1.238 and 1.264). Thus, those respondents that find it justifiable to stretch or overstep legal boundaries, and those respondents that do not necessarily support existing social norms, are also those that are more likely to vote green. This result stresses that the green party is also used as a protest party.

\footnotetext{
${ }^{19} \mathrm{As}$ a consequence, these results on the local versus global problems and green voting are unlikely to extend to other countries where local problems might be evaluated as being more serious.
} 
With respect to our set of controls (sex, marital, children, urban, religious), we find similar results to those obtained from dataset 1 . Our additional variable age, which was unavailable in the previous dataset, shows up as an important determinant of green voting, and may partly work through the health effect of aging. However, the variable confidence in the government is not statistically significantly different from zero here. This stands in contrast to the results from dataset 1, where the satisfaction with the government was highly significant. The difference may come from the fact that in the current dataset the question on confidence is more vague and may be interpreted as a general means to criticize (or support) democracy, while the question in dataset 1 was more precise and asking about the satisfaction with the work of the previous government.

\section{Conclusion}

In this article I have used three different datasets to investigate the links between ecological concern and green voting. I have shown that ecological concern determines green voting in a variety of ways and for several reasons. Firstly, I have constructed a hazard index that measures a voter's distance to nuclear sites and thus his potential fear of being caught up in a disaster or being subject to increased radiation. The econometric results suggest that, even when accounting for potential endogeneities, the hazard index has a statistically significant and robust impact on green voting. Though one might have expected this result since the green party in Germany has always been known for its particularly strong anti-nuclear position, this is the first econometric investigation suggesting that a causal relationship exists.

In addition, the empirical findings suggest that, at least in Germany, local environmental problems seem to be not important enough to drive green voting. However, global environmental problems are viewed as much more serious and the belief on the extent of 
global environmental problems drives green voting.

As a third result, the attitude towards deviant behavior and alternative worldviews or norms shapes the decision to vote green. This result is able to further support the common belief that the green party has always been viewed as a type of protest party. However, since the green party has lost quite some of its protest status and lately became a more conventional party, it is likely that the number of voters from the liberal side will shrink.

Educational attainment and income seem to have a positive effect on green voting, though the results on income are less robust. While it was not possible to find a direct link between income and green voting in the the cross-sectional dataset, the link from income to green voting in the panel dataset was more robust. I am more inclined to believe the results from the panel dataset (this can control for more effects), and the results presented here suggest that green voting increases when voters get richer and more highly educated.

In contrast to the many studies that build upon the stated preference approach and analyze the link between demographic variables and the willingness to undertake prevention expenditure or ecological behavior, we here find very little role for those demographic variables in determining green voting. If ecological concern drives both the willingness to act green and green voting, then the results should be the same. Since they are not, then it is likely that that there are other factors that influence the stated preference results, since the stated preference method only inquires how someone would act, while the voting behavior is a more objective measure. For example, it is known that respondents to sensitive questions may over- or understate their true attitude or behavior (Bradburn, 1983; Tourangeau and Smith, 1996). Hence, the empirical results of the questionnaires on the willingness to undertake green expenditure may be subject to strategic answers, either consciously or subconsciously, through over- or understatement, while voting decisions can be more objective. This is, however, only a suggested explanation and requires further empirical investigation. 
Finally, our assumption of green voting reflecting green preferences may be questionable because parties bundle objectives together. Also, green issues may only be of secondary importance for some voters. Since the voting outcome is either yes or no for the green party, then it could be that our measure of green voting under-represents green attitude if being green is only a secondary objective of voters. As a consequence, our empirical results on ecological concern and green voting should be seen as a lower bound.

In terms of future research, there is really one specific idea that came to mind when working on this project. The question is whether the gap between the ecological attitude, or the willingness to undertake green behavior, could be explained to a large extent by the fact that individuals fear that their efforts are in vain due to free-riding. In this case, those individuals that have a large gap between attitude and behavior due to free-riding fears should be those that vote more strongly in support of their preferences. Another extension could be to add an index of coal power plants, where the proximity to coal power plants might also increase green voting. 


\section{References}

Barro, Robert J, "Rare disasters, asset prices, and welfare costs," The American Economic Review, 2009, pp. 243-264.

Barry, John, "Green Political Theory and the State," Contemporary Political Studies, 1994.

Blomquist, Glenn C. and Whitehead, John C., "Resource quality information and validity of willingness to pay in contingent valuation," Resource and Energy Economics, 1998, 20 (2), 179-196.

Blundell, Richard, Stephen Bond, Michael Devereux, and Fabio Schiantarelli, "Investment and Tobin's Q: Evidence from company panel data," Journal of Econometrics, 1992, 51 (1), 233-257.

Bradburn, Norman M., "Response effects," Handbook of Survey Research, 1983, 1, 289328.

Buenstorf, Guido and Christian Cordes, "Can sustainable consumption be learned? A model of cultural evolution," Ecological Economics, 2008, 67 (4), 646-657.

Bündnix 90/Die Grünen, "Die Zukunft ist grün. Grundsatzprogramm von BÜNDNIS 90/DIE GRÜNEN," April 2002, http://www.gruene-partei.de.

Cameron, Adrian Colin and Pravin K Trivedi, Microeconometrics using stata, Vol. 5, Stata Press College Station, TX, 2009.

Crosby, Lawrence A., James D. Gill, and James R. Taylor, "Consumer/voter behavior in the passage of the Michigan container law," The Journal of Marketing, 1981, pp. 19-32. 
Danielson, Leon and Hoban, Thomas J. and Van Houtven, George and Whitehead, John C., "Measuring the benefits of local publilc goods: environmental quality in Gaston County, North Carolina," Applied Economics, 1995, 27 (12), 1253-1260.

Driscoll, John C. and Aart C. Kraay, "Consistent covariance matrix estimation with spatially dependent panel data," Review of Economics and Statistics, 1998, 80 (4), $549-560$.

Engel, Uwe and Manuela Pötschke, "Willingness to pay for the environment: social structure, value orientations and environmental behaviour in a multilevel perspective," Innovation: The European Journal of Social Science Research, 1998, 11 (3), 315-332.

Engle, Robert F and Hendry, David F and Richard, Jean-Francois, "Exogeneity," Econometrica: Journal of the Econometric Society, 1983, pp. 277-304.

Goodin, Robert E, Green Political Theory, Polity Press Cambridge, 1992.

Hoechle, Daniel, "Robust standard errors for panel regressions with cross-sectional dependence," Stata Journal, 2007, 7 (3), 281.

Inglehart, Ronald, Culture Shift in Advanced Industrial Society, Princeton University Press, 1990.

Israel, Debra and Arik Levinson, "Willingness to pay for environmental quality: testable empirical implications of the growth and environment literature," Contributions in Economic Analysis \& Policy, 2004, 3 (1).

Kahn, Matthew E, "Do greens drive Hummers or hybrids? Environmental ideology as a determinant of consumer choice," Journal of Environmental Economics and Management, 2007, 54 (2), 129-145. 
Mariani, Fabio, Agustin Pérez-Barahona, and Natacha Raffin, "Life expectancy and the environment," Journal of Economic Dynamics and Control, 2010, 34 (4), $798-815$.

Nyborg, Karine, Richard B Howarth, and Kjell Arne Brekke, "Green consumers and public policy: On socially contingent moral motivation," Resource and energy economics, 2006, 28 (4), 351-366.

Popp, David, "Altruism and the demand for environmental quality," Land Economics, 2001, 77 (3), 339-349.

Roodman, David M., "How to do xtabond2: An introduction to difference and system GMM in Stata," Stata Journal, 2009, 9 (1), 86-136.

Schreurs, Miranda and Elim Papadakis, The A to Z of the Green Movement, Vol. 91, Scarecrow Press, 2009.

Schumacher, Ingmar, "The dynamics of environmentalism and the environment," Ecological Economics, 2009, 68 (11), 2842-2849.

, "How beliefs influence prevention expenditure," mimeo, 2013.

and Eric Strobl, "Economic development and losses due to natural disasters: The role of hazard exposure," Ecological Economics, 2011, 72, 97-105.

Stern, Nicholas, The economics of climate change: the Stern review, Cambridge University Press, 2007.

Stevens, Thomas H, Thomas A More, and Ronald J Glass, "Interpretation and temporal stability of CV bids for wildlife existence: a panel study," Land Economics, 1994, pp. 355-363. 
Tiebout, Charles M., "A pure theory of local expenditures," The Journal of Political Economy, 1956, pp. 416-424.

Torgler, Benno and Maria A Garcia-Valiñas, "The determinants of individuals' attitudes towards preventing environmental damage," Ecological economics, 2007, 63 (2), $536-552$.

Tourangeau, Roger and Tom W Smith, "Asking sensitive questions the impact of data collection mode, question format, and question context," Public Opinion Quarterly, 1996, 60 (2), 275-304.

Turaga, Rama Mohana R and Howarth, Richard B and Borsuk, Mark E, "Proenvironmental behavior," Annals of the New York Academy of Sciences, 2010, 1185 (1), 211-224.

U.S. Environmental Protection Agency, The Benefits and Costs of the Clean Air Act from 1990 to 2020, U.S. Environmental Protection Agency, 2011. 


\section{SUPPLEMENTARY INFORMATION - Background information on green party}

In this section I describe more fully why voting for green parties serves to reveal one's green preferences, and also why the focus on green party voting is a relevant one. Furthermore, I give an overview of the voting process in Germany, as well as a discussion of the green party in Germany, the Bündnis 90/Die Grünen.

\subsection{A closer look at green parties}

In the period after the Second World War a vast number of green movements sprung up that had mostly very local environmental problems on their agendas. However, they were seen as having too little impact on the political debate and, as a consequence, green parties formed in order to give these social movements a political voice. The rise of the green parties in the 1980s is thus really a phenomenon that one can, to a large extent, link to the increasing destruction of the local and global environments, coupled with an increasing prosperity that allowed people to become financially independent enough to place more emphasis on ecological concerns. People furthermore noticed that their own impacts on the environment are nearly negligible and that own personal efforts lack a sufficiently strong peer effect on others. Hence, more and more green activists came to believe that solving environmental problems essentially requires supportive political action. As Barry (Barry, 1994) has aptly put it, "[t]o deal with environmental public bads and goods, the state is necessary to assure obedience to the laws that sustainability will require." At the regional or national level, it is after all only the state that can raise taxes, provide financial incentives or introduce regulations such that environmental externalities get internalized by the markets. Hence, green parties formed in the hope that - at the regional, national or international level - the green political voice would obtain a political platform at the 
highest level of the government, such that green preferences are actually taken into account in the political decision-taking process.

It, thus, should not come as a surprise that green parties are the only political parties that have environmental sustainability as their core objective. This is clearly detailed out in the preamble of the Global Greens Charter that nearly all green parties around the world adopt:

We, as citizens of the planet and members of the Global Greens,

United in our awareness that we depend on the Earth's vitality, diversity and beauty, and that it is our responsibility to pass them on, undiminished or even improved, to the next generation

Recognising that the dominant patterns of human production and consumption, based on the dogma of economic growth at any cost and the excessive and wasteful use of natural resources without considering Earth's carrying capacity, are causing extreme deterioration in the environment and a massive extinction of species.

Assert the need for fundamental changes in people's attitudes, values, and ways of producing and living

Resolve to promote a comprehensive concept of sustainability which

protects and restores the integrity of the Earth's ecosystems, with special concern for biodiversity and the natural processes that sustain life

acknowledges the interrelatedness of all ecological, social and economic processes

balances individual interests with the common good

harmonises freedom with responsibility

welcomes diversity within unity

reconciles short term objectives with long term goals

ensures that future generations have the same right as the present generation to natural and cultural benefits

$\cdots$

Commit ourselves as Green parties and political movements from around the world to implement these interrelated principles and to create a global partnership in support of their fulfilment.

This political agenda clearly lays out the objectives of the green parties across the world. Though there are other parties that have, since then, integrated environmental concerns 
into their agendas, it is also well-known that they sub-due these environmental objectives to (in general) economic ones. Thus, one would expect that voting for green parties should reflect that environmental issues are top priority.

At the same time, it is also true that green parties, in addition to their primary objective of environmental sustainability, tend to have other secondary objectives, like women rights or social equality. As a consequence, voting for the green party could, in addition, be due to these alternative protest type criteria. Nevertheless, as Schreurs and Papadakis (Schreurs and Papadakis, 2009) note, "the agenda of green political groups and organizations includes much that is not specifically green, even though these preoccupations or values can be accommodated by what Goodin (Goodin, 1992) refers to as a "green theory" or philosophy of value. Among these values are the focus on postmaterialism (see Inglehart (Inglehart, 1990)), the notion of nature as irreplaceable, the ideas of sustainability and sustainable development, the long-term consequences of our current actions, and the emancipation of oppressed groups (for instance, minorities, the poor, and women). Goodin describes these values as corollaries to a green theory value." Consequently, there is a tendency in the literature to view postmaterialistic values as highly correlated with attitudes towards the environment. What I, therefore, assume, is that the clear objective of the green parties helps in attracting those voters that place priority on environmental problems. The potential measurement error of including those that vote the green party for other reasons but strictly environmental ones will be small, since these other reasons tend to strongly correlate with environmental attitudes.

\subsection{Voting process in Germany}

This section is intended for those readers that may wish for some background information on the voting process in Germany. Those readers familiar with the voting process in Germany may skip this section. 
Political decisions in Germany are taken according to the so-called bicameral parliamentary system. This consists of the Lower House of the German Parliament (Bundestag), and the Federal Council or Upper House (Bundesrat). Elections for the Lower House are generally every four, while those for the Upper House are every four or five years.

The Lower House is the main organ that decides about legislation, the national budget plan, chooses the chancellor, and, for example, decides on the use of the army. The 598 members of the Lower House are voted directly through a mix between proportional representation and majority voting. Every voter has two votes. With the first vote one chooses a candidate that then would directly enter the Lower House if he or she receives the majority of the votes in the voter's administrative district. There are 299 of those administrative districts in Germany, and every one of these districts is supposed to hold approximately the same number of voters. Each administrative district sends the candidate who received most votes to the Lower House. With their second vote, voters do not vote directly for their preferred candidate, but they vote for their preferred party. Votes are then aggregated nationally and all parties that nationally received more than five percent of all votes may enter pre-selected candidates into the Lower House in proportion to their share of national votes. In case there are more direct candidates of a party for the Lower House than that party's share of national votes would allow for, then these direct candidates are nevertheless admitted to the Lower House via so-called excess mandates (Überhangsmandat). Hence, under special cases the Lower Houses may have more than 598 members. $^{20}$

The Upper House is the constitutional body that has a veto right for most decisions taken in the Lower House. It consists of members of the government of the sixteen federal states in Germany, where each state holds a certain number of votes that increases with its population, albeit at a decreasing rate. Every federal state has its own voting mechanism,

\footnotetext{
${ }^{20}$ For example, in the 2005 election there were 16 excess mandates.
} 
which is either proportional representation, or majority voting, or a mix between the two.

\subsection{The green party in Germany}

The green party in Germany was essentially founded in 1993 when the German Green Party merged with the Bündnis 90. Since then it is known as Bündnis 90/Die Grünen. We shall simply call it the green party here. The core beliefs of the green party are well-summarized in the preamble to its fundamental program (Bündnis 90/Die Grünen (Bündnix 90/Die Grünen, April 2002, http://www.gruene-partei.de), p. 10, own translation): "We combine ecology, autonomy, enlarged justice and living democracy. With the same emphasis we engage ourselves for non-violence and human rights." The belief of the green party is that the approach of sustainable development in the ecological field can be used for and applied to other political agendas, too.

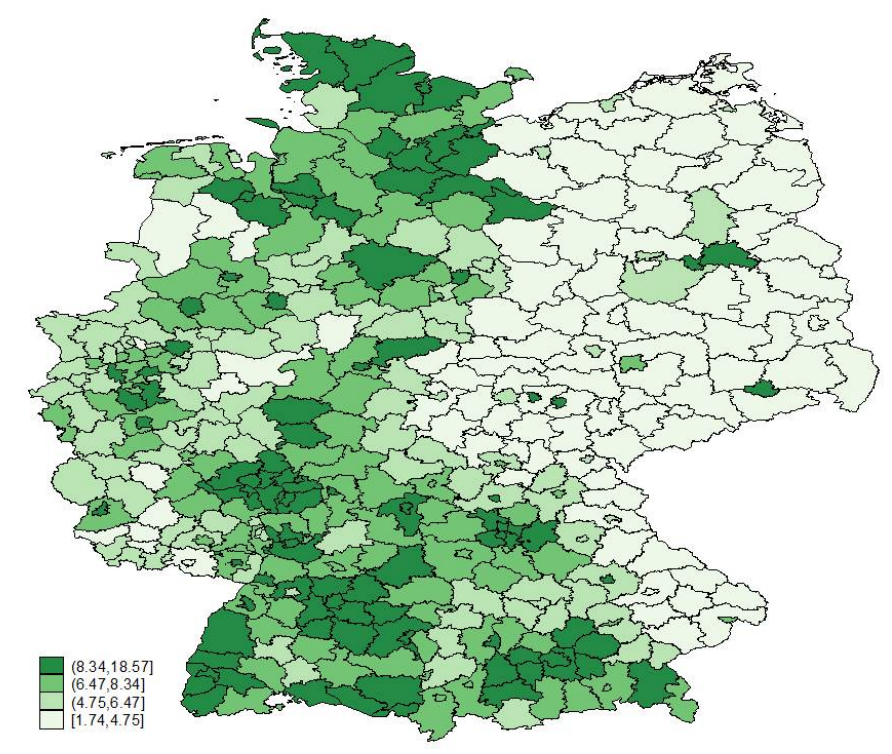

Figure 2: Green voting 2009

One of the main objectives of the green party is to stop the use of atomic power in Germany. The party has always been associated with this as one of its core principles. The belief is that "[t]he atomic energy is not a solution for the energy problem, but it 
creates only unpredictable new problems." (Bündnis 90/Die Grünen (Bündnix 90/Die Grünen, April 2002, http://www.gruene-partei.de), p.30) Consequently, one would expect that the number of atomic power plants, the government's plans for energy production, or the proximity to atomic plants may be criteria to vote for the green party. This point will be further investigated in section 2.1. The emphasis that the green party places on stopping nuclear energy can be understood when one looks at its success to implement its agenda while in power. In the 1998 federal election the green party received $6.7 \%$ of all votes for the Lower House and together with the stronger Social Democratic Party (SPD) it, for the first time, formed the government. In 2000, the red-green coalition decided, based on the lobbying of the green party, to phase out atomic power in Germany by 2020 . It continued to form the government with the SDP in 2002, and subsequently imposed pressures that helped to shut down two nuclear power plants, one in 2003, the other in 2005. Since the 2005 election, the green party has played the role of an opposition party, since it was unable to enter a governmental coalition.

An example for the voting outcome of the second vote for the green party for the Lower House at the county level for 2009 is given in Figure 2. This consists of votes from 295 counties (Landkreise) and 107 urban districts (kreisfreie Städte) that are not associated with a county. ${ }^{21}$ One can see that green voting tends to cluster in western Germany, while the counties in the former region of East Germany have relatively fewer votes directed towards the green party.

\footnotetext{
${ }^{21}$ The 299 administrative units consist of 295 counties and 107 urban districts. Some administrative units consist of several counties or urban districts depending to population size.
} 


\section{Tables}

Table 4: Summary statistics: cross-section dataset 1

\begin{tabular}{lccc}
\hline \multicolumn{1}{c}{ Variable } & Mean & Std. Dev. & N \\
\hline green $_{i}$ & 0.069 & 0.253 & 2,835 \\
nuclear $_{i}$ & 0.483 & 0.5 & 2,835 \\
education_d1 $_{i}$ & 0.019 & 0.137 & 2,835 \\
education_d2 & 0.303 & 0.46 & 2,835 \\
education_d $_{i}$ & 0.127 & 0.333 & 2,835 \\
education_d $_{i}$ & 0.134 & 0.341 & 2,835 \\
interest $_{i}$ & 0.346 & 0.476 & 2,835 \\
gov_sat $_{i}$ & 0.586 & 0.493 & 2,835 \\
TVnews $_{i}$ & 0.758 & 0.429 & 2,835 \\
election $_{i}$ & 1.492 & 0.5 & 2,835 \\
\hline
\end{tabular}


Table 5: Cross-section dataset 1

\begin{tabular}{|c|c|c|c|c|c|}
\hline VARIABLES & $\begin{array}{l}(13) \\
\text { green }\end{array}$ & $\begin{array}{l}(14) \\
\text { green }\end{array}$ & $\begin{array}{l}(15) \\
\text { green }\end{array}$ & $\begin{array}{l}(16) \\
\text { green }\end{array}$ & $\begin{array}{l}(17) \\
\text { green }\end{array}$ \\
\hline nuclear & $\begin{array}{c}4.404^{* * *} \\
(1.003)\end{array}$ & $\begin{array}{c}4.416^{* * *} \\
(0.983)\end{array}$ & $\begin{array}{c}3.285^{* * *} \\
(0.675)\end{array}$ & $\begin{array}{c}3.227^{* * *} \\
(0.679)\end{array}$ & $\begin{array}{c}2.784^{* * *} \\
(0.727)\end{array}$ \\
\hline education_d1 & & & $\begin{array}{c}0.728 \\
(0.434)\end{array}$ & $\begin{array}{c}0.673 \\
(0.418)\end{array}$ & $\begin{array}{c}0.667 \\
(0.404)\end{array}$ \\
\hline education_d2 & & & $\begin{array}{c}1.899^{* * *} \\
(0.339)\end{array}$ & $\begin{array}{c}2.149^{* * *} \\
(0.412)\end{array}$ & $\begin{array}{l}1.769^{* *} \\
(0.392)\end{array}$ \\
\hline education_d3 & & & $\begin{array}{c}3.528^{* * *} \\
(0.569)\end{array}$ & $\begin{array}{c}3.604^{* * *} \\
(0.626)\end{array}$ & $\begin{array}{c}2.702^{* * *} \\
(0.497)\end{array}$ \\
\hline education_d4 & & & $\begin{array}{c}4.698^{* * *} \\
(0.838)\end{array}$ & $\begin{array}{c}5.067^{* * *} \\
(0.966)\end{array}$ & $\begin{array}{c}4.164^{* * *} \\
(0.940)\end{array}$ \\
\hline interest & & & $\begin{array}{c}1.697^{* * *} \\
(0.240)\end{array}$ & $\begin{array}{c}1.683^{* * *} \\
(0.261)\end{array}$ & $\begin{array}{c}1.613^{* * *} \\
(0.271)\end{array}$ \\
\hline gov_sat & & & $\begin{array}{c}5.306^{* * *} \\
(1.797)\end{array}$ & $\begin{array}{c}5.435^{* * *} \\
(1.892)\end{array}$ & $\begin{array}{c}5.580^{* * * *} \\
(1.628)\end{array}$ \\
\hline TVnews & & & $\begin{array}{c}0.640 * * * \\
(0.0941)\end{array}$ & $\begin{array}{c}0.642^{* * *} \\
(0.0934)\end{array}$ & $\begin{array}{c}0.635^{* *} \\
(0.126)\end{array}$ \\
\hline sex & & & & & $\begin{array}{l}1.255 \\
(0.208)\end{array}$ \\
\hline marital & & & & & $\begin{array}{c}0.854 \\
(0.132)\end{array}$ \\
\hline just & & & & & $\begin{array}{c}0.977 \\
(0.146)\end{array}$ \\
\hline status & & & & & $\begin{array}{c}1.192 \\
(0.143)\end{array}$ \\
\hline diff_d1 & & & & & $\begin{array}{c}1.320 \\
(0.843)\end{array}$ \\
\hline diff_d2 & & & & & $\begin{array}{c}1.284 \\
(0.768)\end{array}$ \\
\hline diff_d3 & & & & & $\begin{array}{l}1.250 \\
(0.729)\end{array}$ \\
\hline diff_d4 & & & & & $\begin{array}{c}1.358 \\
(0.880)\end{array}$ \\
\hline election & $\begin{array}{l}1.025 \\
(0.112)\end{array}$ & $\begin{array}{l}1.048 \\
(0.115)\end{array}$ & $\begin{array}{c}1.152 \\
(0.123)\end{array}$ & $\begin{array}{l}1.212^{*} \\
(0.130)\end{array}$ & $\begin{array}{c}1.201 \\
(0.138)\end{array}$ \\
\hline Constant & $\begin{array}{c}0.0277^{* * *} \\
(0.00800)\end{array}$ & $\begin{array}{c}0.0246^{* * *} \\
(0.00591)\end{array}$ & $\begin{array}{c}0.00426^{* * *} \\
(0.00225)\end{array}$ & $\begin{array}{c}0.00353^{* * *} \\
(0.00192)\end{array}$ & $\begin{array}{c}0.00239^{* * *} \\
(0.00137)\end{array}$ \\
\hline Observations & 2,835 & 2,835 & 2,835 & 2,835 & 2,428 \\
\hline $\begin{array}{c}\text { Pseudo R-sq. } \\
\text { Sample }\end{array}$ & $\begin{array}{c}0.059 \\
\text { Germany }\end{array}$ & $\begin{array}{c}0.084 \\
\text { Germany }\end{array}$ & $\begin{array}{c}0.173 \\
\text { Germany }\end{array}$ & $\begin{array}{c}0.196 \\
\text { Germany }\end{array}$ & $\begin{array}{c}0.184 \\
\text { Germany }\end{array}$ \\
\hline $\begin{array}{l}\text { Stand. Err. } \\
\text { Dummies }\end{array}$ & rob. \& clust. & $\begin{array}{l}\text { rob. \& clust. } \\
\text { state }\end{array}$ & rob. \& clust. & $\begin{array}{l}\text { rob. \& clust. } \\
\text { state }\end{array}$ & $\begin{array}{l}\text { rob. \& clust. } \\
\text { state }\end{array}$ \\
\hline HL test ( $p$-val) & 0.791 & 0.71 & 0.537 & 0.399 & 0.226 \\
\hline ML test (p-val) & 0.568 & 0.814 & 0.04 & 0.18 & 0.183 \\
\hline
\end{tabular}

Robust standard errors in parentheses

${ }^{* * *} \mathrm{p}<0.01,{ }^{* *} \mathrm{p}<0.05,{ }^{*} \mathrm{p}<0.1$ 
Table 6: Variable description - cross sectional dataset 1

\begin{tabular}{|c|c|}
\hline Variable & Description \\
\hline green & $\begin{array}{l}\text { To which party did you give your second vote }{ }^{22}(0 \text { - other parties; } 1 \text { - Bündnis } \\
90 / \text { Die Grünen })\end{array}$ \\
\hline$\overline{\text { nuclear }}$ & $\begin{array}{l}\text { Which opinion do you have on nuclear energy? }(\overline{1}-\text { further increase of nuclear } \\
\text { energy, } 7 \text { - immediate stop of nuclear power plants), recoded as }(1,2 \text { and } 3=0) \\
\text { and }(4,5,6 \text { and } 7=1)\end{array}$ \\
\hline éducation & $\begin{array}{l}\text { What is your highest educational level? reference level: lower secondary edu- } \\
\text { cation, education_d1: still student; education_d2: ; education_d3: A-level; } \\
\text { education_d4: university level education }\end{array}$ \\
\hline interest & $\begin{array}{l}\text { How strong is your interest for politics? ( } 1 \text { - very strong; } 5 \text { - no interest), } \\
\text { recoded as }(1 \text { and } 2=1)(3 \text { to } 5=0)\end{array}$ \\
\hline gov_sat & $\begin{array}{l}\text { Were you satisfied with the previous government (SPD-Bündnis } 90 / \text { Die Grü- } \\
\text { nen }) \text { in Berlin? }(+5-\text { completely satisfied; }-5 \text { - totally unsatisfied), recoded as } \\
(0 \text { to }+5=1)(-5 \text { to }-1=0)\end{array}$ \\
\hline TVnews & $\begin{array}{l}\text { On average, on how many days of the week do you see news programs in the } \\
\text { first and second program on TV } ?^{23} \text { answers range from } 0 \text { to } 7 \text { days; coded as } \\
(0 \text { to } 3=0) \text { and }(4 \text { to } 7=1)\end{array}$ \\
\hline sex & $0=$ male, $1=$ female \\
\hline married & gle, $1=$ married \\
\hline religious & $\begin{array}{l}\text { How often do you attend religious services? ( } 1 \text { - once a week or more; } 6 \text { - never), } \\
\text { recoded as }(1,2 \text { and } 3=1) \text { and }(4,5 \text { and } 6=0)\end{array}$ \\
\hline class & $\begin{array}{l}\text { To which social class do you attribute yourself to, working class, middle class } \\
\text { or upper class? recoded as three dummies }\end{array}$ \\
\hline election & dummy for 0 - before election; 1 - after election \\
\hline diff_d1-d & $\begin{array}{l}\text { There is a difference between parties? (diff_- } \mathrm{d} 1=1 \text { if not true at all, diff__ } \mathrm{d} 2=1 \\
\text { if not true, diff_d } 3=1 \text { if maybe, diff_d } 4=1 \text { if mostly true, else all }=0 \text { ) }\end{array}$ \\
\hline
\end{tabular}


Table 7: Variable description - cross sectional dataset 2

\begin{tabular}{|c|c|}
\hline Variable & Description \\
\hline green & $\begin{array}{l}\text { If there were a national/general election tomorrow, for which party on this list } \\
\text { would you vote? ( } 0 \text { - other parties; } 1 \text { - Bündnis } 90 / \text { Die Grünen) }\end{array}$ \\
\hline $\mathrm{gr}_{-}^{-}{ }_{\mathrm{loc}}^{-}$ & $\begin{array}{l}\text { This is the sum of each respondent's answers to the following question: I am } \\
\text { going to read out a list of environmental problems facing many communities. } \\
\text { Please, tell me how serious you consider each one to be here in your own com- } \\
\text { munity: 1) water quality, 2) poor air quality, } 3 \text { ) poor sewage and sanitation; } 1- \\
\text { very serious, } 4 \text { - not serious at all, gr_loc is the sum of answers to each question }\end{array}$ \\
\hline gr_glo & $\begin{array}{l}\text { This is the sum of each respondent's answers to the following question: Now } \\
\text { letŠs consider environmental problems in the world as a whole. Please, tell me } \\
\text { how serious you consider each of the following to be for the world as a whole. } \\
: \text { 1) global warming or the greenhouse effect, 2) loss of plant or animal species } \\
\text { or biodiversity, } 3 \text { ) pollution of rivers, lakes and oceans; } 1 \text { - very serious, } 4 \text { - not } \\
\text { serious at all, gr_glo is the sum of answers to each question }\end{array}$ \\
\hline gr_i & This variable is the sum of $g r$ \\
\hline & $\begin{array}{l}\bar{A} \overline{l l} \text { in all, how would you describe your state of health these days? Would you } \\
\text { say it is }(1 \text { - very good, } 4 \text { - poor }) \text {, recoded as }(1 \text { and } 2=1)(3 \text { and } 4=0)\end{array}$ \\
\hline education & $\begin{array}{l}\text { What is the highest educational level that you have attained?; reference level: } \\
\text { lower secondary education, education2: incomplete A-level to A-level, educa- } \\
\text { tion3: incomplete university to university degree }\end{array}$ \\
\hline conf_gov & $\begin{array}{l}\text { Could you tell me how much confidence you have in the government? ( } 1 \text { - a } \\
\text { great deal, } 4 \text { - none at all }) \text {, recoded as }(1 \text { and } 2=1)(3 \text { and } 4=0)\end{array}$ \\
\hline just_deviant & $\begin{array}{l}\text { The average across each respondent's answer to the following four questions: } \\
\text { Please tell me for each of the following actions whether you think it can always } \\
\text { be justified, never be justified, or something in between: } 1 \text { ) claiming govern- } \\
\text { ment benefits, } 2 \text { ) avoiding a fare on public transport, } 3 \text { ) cheating on taxes, } 4) \\
\text { someone accepting a bribe; ( } 1 \text { - never justifiable, } 10 \text { - always justifiable) }\end{array}$ \\
\hline just_altern & $\begin{array}{l}\text { The average across each respondent's answer to the following five questions: } \\
\text { Please tell me for each of the following actions whether you think it can always } \\
\text { be justified, never be justified, or something in between: } 1 \text { ) homosexuality, } 2 \text { ) } \\
\text { prostitution, } 3 \text { ) abortion, } 4 \text { ) divorce, } 5 \text { ) euthanasia; ( } 1 \text { - never justifiable, 10- } \\
\text { always justifiable) }\end{array}$ \\
\hline religious & $\begin{array}{l}\text { How often do you attend religious services? ( } 1 \text { - once a week or more; } 6 \text { - never), } \\
\text { recoded as }(1,2 \text { and } 3=1) \text { and }(4,5 \text { and } 6=0)\end{array}$ \\
\hline age & corresponds to actual age of respondent \\
\hline $\operatorname{sex}$ & $0=$ male, $1=$ female \\
\hline marital & marital status, $0=$ single, $1=$ married \\
\hline children & number of children of respondent \\
\hline urban & $\begin{array}{l}\text { What is the size of the town you live in? takes a } 1 \text { for population larger than } \\
50,000,0 \text { if population is less than } 50,000 \text {. }\end{array}$ \\
\hline
\end{tabular}


Table 8: Summary statistics: cross-sectional dataset 2

\begin{tabular}{lccc}
\hline \multicolumn{1}{c}{ Variable } & Mean & Std. Dev. & N \\
\hline green $_{i}$ & 0.077 & 0.267 & 1,343 \\
gr_loc $_{i}$ & 9.229 & 2.963 & 1,343 \\
gr_glo $_{i}$ & 5.079 & 1.704 & 1,343 \\
health $_{i}$ & 0.686 & 0.464 & 1,343 \\
education $_{i}$ & 0.433 & 0.496 & 1,343 \\
education $_{i}$ & 0.158 & 0.365 & 1,343 \\
conf_gov $_{i}$ & 0.275 & 0.447 & 1,343 \\
just_deviant $_{i}$ & 2.003 & 1.337 & 1,343 \\
just_altern $_{i}$ & 5.382 & 2.117 & 1,343 \\
religious $_{i}$ & 0.195 & 0.396 & 1,343 \\
urban $_{i}$ & 0.349 & 0.477 & 1,343 \\
age $_{i}$ & 50.397 & 17.437 & 1,343 \\
sex $_{i}$ & 0.551 & 0.498 & 1,343 \\
marital $_{i}$ & 0.66 & 0.474 & 1,343 \\
children $_{i}$ & 1.573 & 1.299 & 1,343 \\
\hline
\end{tabular}


Table 9: Cross-section dataset 2

\begin{tabular}{|c|c|c|c|c|}
\hline VARIABLES & (18) & (19) & (20) & (21) \\
\hline gr_i & $\begin{array}{c}0.911^{* * *} \\
(0.0240)\end{array}$ & $\begin{array}{c}0.922 * * * \\
(0.0268)\end{array}$ & & \\
\hline gr_loc & & & $\begin{array}{c}0.958 \\
(0.0334)\end{array}$ & $\begin{array}{c}0.976 \\
(0.0350)\end{array}$ \\
\hline gr_glo & & & $\begin{array}{c}0.814^{* * *} \\
(0.0577)\end{array}$ & $\begin{array}{c}0.815^{* * *} \\
(0.0590)\end{array}$ \\
\hline health & $\begin{array}{c}2.122^{* * *} \\
(0.588)\end{array}$ & $\begin{array}{c}1.503 \\
(0.449)\end{array}$ & $\begin{array}{c}1.539 \\
(0.462)\end{array}$ & $\begin{array}{c}1.430 \\
(0.432)\end{array}$ \\
\hline educlass2 & $\begin{array}{c}2.148^{* * *} \\
(0.563)\end{array}$ & $\begin{array}{l}1.400 \\
(0.380)\end{array}$ & $\begin{array}{c}1.360 \\
(0.372)\end{array}$ & $\begin{array}{c}1.358 \\
(0.374)\end{array}$ \\
\hline educlass3 & $\begin{array}{c}2.628^{* * *} \\
(0.809)\end{array}$ & $\begin{array}{c}2.551^{* * *} \\
(0.810)\end{array}$ & $\begin{array}{c}2.391^{* * *} \\
(0.774)\end{array}$ & $\begin{array}{l}2.090^{* *} \\
(0.697)\end{array}$ \\
\hline confidence & & $\begin{array}{c}0.754 \\
(0.195)\end{array}$ & $\begin{array}{c}0.748 \\
(0.193)\end{array}$ & $\begin{array}{c}0.777 \\
(0.207)\end{array}$ \\
\hline just_deviant & & & & $\begin{array}{l}1.238^{* * *} \\
(0.0871)\end{array}$ \\
\hline just_altern & & & & $\begin{array}{c}1.264^{* * *} \\
(0.0838)\end{array}$ \\
\hline religious & & $\begin{array}{c}1.012 \\
(0.316)\end{array}$ & $\begin{array}{c}1.006 \\
(0.312)\end{array}$ & $\begin{array}{c}1.484 \\
(0.491)\end{array}$ \\
\hline urban & & $\begin{array}{c}1.312 \\
(0.285)\end{array}$ & $\begin{array}{c}1.342 \\
(0.294)\end{array}$ & $\begin{array}{l}1.256 \\
(0.280)\end{array}$ \\
\hline age & & $\begin{array}{l}0.970 * * * \\
(0.00814)\end{array}$ & $\begin{array}{c}0.970 * * * \\
(0.00824)\end{array}$ & $\begin{array}{c}0.978^{* *} \\
(0.00897)\end{array}$ \\
\hline $\operatorname{sex}$ & & $\begin{array}{c}1.272 \\
(0.283)\end{array}$ & $\begin{array}{l}1.209 \\
(0.274)\end{array}$ & $\begin{array}{c}1.208 \\
(0.278)\end{array}$ \\
\hline marital & & $\begin{array}{c}0.866 \\
(0.206)\end{array}$ & $\begin{array}{c}0.843 \\
(0.202)\end{array}$ & $\begin{array}{c}0.891 \\
(0.217)\end{array}$ \\
\hline children & & $\begin{array}{l}0.781^{*} \\
(0.107)\end{array}$ & $\begin{array}{l}0.784^{*} \\
(0.108)\end{array}$ & $\begin{array}{c}0.817 \\
(0.114)\end{array}$ \\
\hline Constant & $\begin{array}{c}0.0958^{* * *} \\
(0.0469)\end{array}$ & $\begin{array}{c}0.634 \\
(0.470)\end{array}$ & $\begin{array}{c}0.840 \\
(0.648)\end{array}$ & $\begin{array}{c}0.0724^{* * *} \\
(0.0703)\end{array}$ \\
\hline Observations & 1,343 & 1,343 & 1,343 & 1,343 \\
\hline Pseudo R-sq. & 0.056 & 0.12 & 0.126 & 0.157 \\
\hline $\begin{array}{l}\text { Sample } \\
\text { Stand. Err. }\end{array}$ & $\begin{array}{c}\text { Germany } \\
\text { robust }\end{array}$ & $\begin{array}{c}\text { Germany } \\
\text { robust }\end{array}$ & $\begin{array}{c}\text { Germany } \\
\text { robust }\end{array}$ & $\begin{array}{c}\text { Germany } \\
\text { robust }\end{array}$ \\
\hline HL test ( $p$-val) & 0.943 & 0.56 & 0.657 & 0.81 \\
\hline LM test (p-val) & 0.951 & 0.487 & 0.595 & 0.899 \\
\hline
\end{tabular}

Robust standard errors in parentheses

*** $p<0.01,{ }^{* *} p<0.05,{ }^{*} p<0.1$ 